Pacific Journal of Mathematic 


\title{
EXPANSIVE AUTOMORPHISMS OF BANACH SPACES, II
}

\author{
JAMES H. HEDLUND
}

\begin{abstract}
An automorphism of a complex Banach space is shown to be uniformly expansive if and only if its approximate point spectrum is disjoint from the unit circle.
\end{abstract}

The problem of giving a spectral characterization of the property that an operator be uniformly expansive was investigated in [2], but the theorem stated above was obtained only for automorphisms of a Hilbert space. The proof given in this note is both more general and more transparent than the special version. We also note some topological properties of the various classes of expansive operators in the space of all invertible operators.

1. Uniformly expansive automorphisms. If $T$ is an automorphism (a bounded, invertible, linear operator) on a complex Banach space $X$ denote its spectrum by $\Lambda(T)$, its compression spectrum by $\Gamma(T)$, its approximate point spectrum by $\Pi(T)$, and its point spectrum by $I_{0}(T)$. Denote the unit circle $\{\lambda:|\lambda|=1\}$ in the complex plane by $C$. The automorphism $T$ is said to be

(1) expansive if for each $x \in X$ with $\|x\|=1$ there exists some non-zero integer $n$ with $\left\|T^{n} x\right\| \geqq 2$;

(2) uniformly expansive if there exists some positive integer $n$ such that if $x \in X$ with $\|x\|=1$ then either $\left\|T^{n} x\right\| \geqq 2$ or $\left\|T^{-n} x\right\| \geqq 2$;

(3) hyperbolic if there exists a splitting $X=X_{s} \oplus X_{u}, T=$ $T_{s} \oplus T_{u}$, where $X_{s}$ and $X_{u}$ are closed $T$-invariant linear subspaces of $X, T_{s}=T \mid X_{s}$ is a proper contraction, and $T_{u}=T \mid X_{u}$ is a proper dilation.

A discussion of these classes of automorphisms may be found in [2].

It is well-known [2, Lemma 1] that an automorphism $T$ is hyperbolic if and only if $\Lambda(T) \cap C=\varnothing$. The principal result weakens both conditions.

THEOREM 1. Let $T$ be an automorphism of a complex Banach space $X$. Then $T$ is uniformly expansive if and only if $I(T) \cap$ $C=\phi$.

The proof requires the Banach space version of an interesting numerical lemma. 
Lemma 1. Given any complex numbers $c_{1}, \cdots, c_{s}$ there exists $\lambda \in C$ such that $\sum_{j=1}^{s} \lambda^{j} c_{j} \geq 0$.

\section{Proof. [2, Lemma 2]}

Lemma 2. Given any complex numbers $c_{-r}, \cdots, c_{s}$ with $c_{0} \neq 0$ there exists $\lambda \in C$ such that $\left|\sum_{j=-r}^{s} \lambda^{j} c_{j}\right| \geq\left|c_{0}\right|$.

Proof. We may assume that $c_{0}>0$ : otherwise set $\mathrm{d}_{j}=\left(\bar{c}_{0} /\left|c_{0}\right|\right) c_{j}$ and proceed. Let $f(\lambda)=\sum_{j=1}^{s} \lambda^{j} c_{j}, g(\lambda)=\sum_{j=-r}^{-1} \lambda^{j} c_{j}$, and $h(\lambda)=$ $\sum_{j=1}^{r} \lambda^{j} \bar{c}_{-j}$. Since $\lambda^{-j}=(\bar{\lambda})^{j}$ for $\lambda \in C$ it follows that $\operatorname{Re} g(\lambda)=\operatorname{Re} h(\lambda)$, and therefore $\operatorname{Re}[f(\lambda)+g(\lambda)]=\operatorname{Re}[f(\lambda)+h(\lambda)]$. Now $f(\lambda)+h(\lambda)$ is a polynomial in $\lambda$; by Lemma 1 there exists $\lambda \in C$ such that $f(\lambda)+$ $h(\lambda) \geq 0$. Thus $f(\lambda)+h(\lambda)+c_{0} \geq c_{0}$, and

$$
\left|\sum_{j=-r}^{s} \lambda^{j} c_{j}\right| \geq \operatorname{Re}\left(\sum_{j=-r}^{s} \lambda^{j} c_{j}\right)=\operatorname{Re}\left[f(\lambda)+h(\lambda)+c_{0}\right] \geq c_{0} .
$$

Lemma 3. Given any vectors $x_{-r}, \cdots, x_{s}$ in a Banach space $X$ with $x_{0} \neq 0$ there exists $\lambda \in C$ such that

$$
\left\|\sum_{j=-r}^{s} \lambda^{j} x_{j}\right\| \geqq\left\|x_{0}\right\|
$$

Proof. By the Hahn-Banach Theorem choose $x^{*} \in X^{*}$ with $\left\|x^{*}\right\|=1$ and $x^{*}\left(x_{0}\right)=\left\|x_{0}\right\|$. It suffices to find $\lambda \in C$ with

$$
\left|x^{*}\left(\sum_{j=-r}^{s} \lambda^{j} x_{j}\right)\right| \geqq\left|x^{*}\left(x_{0}\right)\right|
$$

Set $c_{j}=x^{*}\left(x_{j}\right)$ and apply Lemma 2: there exists $\lambda \in C$ such that

$$
\left|x^{*}\left(\sum_{j=-\boldsymbol{r}}^{s} \lambda^{j} x_{j}\right)\right|=\left|\sum_{j=-\boldsymbol{r}}^{s} \lambda^{j} c_{j}\right| \geqq\left|c_{0}\right|=\left|x^{*}\left(x_{0}\right)\right| \text {. }
$$

Proof of Theorem 1. Necessity is proved in [2, Theorem 1]. To prove sufficiency, suppose that $T$ is not uniformly expansive. Then for each positive integer $n$ there exists $x_{n} \in X$ with $\left\|x_{n}\right\|=1$ and $\max \left\{\left\|T^{n} x_{n}\right\|,\left\|T^{-n} x_{n}\right\|\right\}<2$. For infinitely many $n$ we produce a vector $y_{n} \in X$ and a number $\lambda_{n} \in C$ such that $\left\|\left(T-\lambda_{n}^{-1}\right) y_{n}\right\| /\left\|y_{n}\right\| \rightarrow 0$. This will suffice. In fact, if $\mu \in C$ is a limit point of $\left\{\lambda_{n}^{-1}\right\}$ choose a subsequence $\left\{\lambda_{m}^{-1}\right\}$ of $\left\{\lambda_{n}^{-1}\right\}$ with $\lambda_{m}^{-1} \rightarrow \mu$. Then

$$
\left\|(T-\mu) y_{m}\right\| /\left\|y_{m}\right\| \leqq\left\|\left(T-\lambda_{m}^{-1}\right) y_{m}\right\| /\left\|y_{m}\right\|+\left|\lambda_{m}^{-1}-\mu\right| \text {. }
$$

The right-hand side approaches 0 as $m \rightarrow \infty$, so that $\mu \in \Pi(T)$.

To construct $y_{n}$ we must consider two cases. Define 


$$
\phi(n)=\max _{k=-n, 0} \sup _{\lambda \in C}\left\|\sum_{j=k}^{k+n-1} \lambda^{j} T^{j} x_{n}\right\| .
$$

Case 1. $\phi(n)$ is unbounded. Fix $n$, choose $k$ where the maximum in the definition of $\phi$ is attained, and let $\lambda_{n}$ be the $\lambda \in C$ where the supremum is attained. Define

$$
y_{n}=\sum_{j=k}^{k+n-1} \lambda_{n}^{j} T^{j} x_{n}
$$

so that $\left\|y_{n}\right\|=\phi(n)$. Now

$$
\left(T-\lambda_{n}^{-1}\right) y_{n}=\lambda_{n}^{n-1} T^{n} x_{n}-\lambda_{n}^{-1} x_{n} \text { if } k=0,
$$

and

$$
\left(T-\lambda_{n}^{-1}\right) y_{n}=\lambda_{n}^{-1} x_{n}-\lambda_{n}^{-n-1} T^{-n} x_{n} \text { if } k=-n .
$$

In either event,

$$
\left\|\left(T-\lambda_{n}^{-1}\right) y_{n}\right\| \leqq 3 \text {. Thus }\left\|\left(T-\lambda_{n}^{-1}\right) y_{n}\right\| /\left\|y_{n}\right\| \leqq 3 / \phi(n) .
$$

Since $\dot{\phi}(n)$ is unbounded, $3 / \dot{\phi}\left(n_{j}\right) \rightarrow 0$ for some subsequence $n_{j} \rightarrow \infty$.

Case 2. $\phi(n)$ is bounded. Assume that $\phi(n) \leqq A$ for all $n$ and define

$$
y_{n}=\sum_{j=-n}^{-1}(n+1+j) \lambda_{n}^{j} T^{j} x_{n}+\sum_{j=0}^{n-1}(n-j) \lambda_{n}^{j} T^{j} x_{n},
$$

where we choose $\lambda_{n} \in C$ by Lemma 3 to insure that $\left\|y_{n}\right\| \geqq n$, the norm of the term with index 0 .

$$
\begin{aligned}
\left\|\left(T-\lambda_{n}^{-1}\right) y_{n}\right\| & =\left\|-\sum_{j=-n}^{-1} \lambda_{n}^{j-1} T^{j} x_{n}+\sum_{j=1}^{n} \lambda_{n}^{j-1} T^{j} x_{n}\right\| \\
& \leqq\left\|\sum_{j=-n}^{-1} \lambda_{n}^{j} T^{j} x_{n}\right\|+\left\|T\left(\sum_{j=0}^{n-1} \lambda_{n}^{j} T^{j} x_{n}\right)\right\| \\
& \leqq A(1+\|T\|) .
\end{aligned}
$$

Hence

$$
\left\|\left(T-\lambda_{n}^{-1}\right) y_{n}\right\| /\left\|y_{n}\right\| \leqq A(1+\|T\|) / n \rightarrow 0 .
$$

Note that the hypothesis that $T$ is not uniformly expansive is not used in Case 2. But it is easy to see directly (by Lemma 3) that $T$ is not uniformly expansive if $\phi(n)$ is bounded. Note also that it follows immediately from Theorem 1 that a hyperbolic automorphism is uniformly expansive.

2. Density. Denote the class of all hyperbolic automorphisms of a fixed Banach space $X$ by $\mathscr{H}$, of uniformly expansive by $\mathscr{C} \mathscr{E}$, of expansive by $\mathscr{E}$, of all automorphisms by $\mathscr{F}$, and of all bounded linear 
operators by $\mathscr{B}$. If $\operatorname{dim} X<\infty$ then $\mathscr{H}=\mathscr{U} \mathscr{E}=\mathscr{E}$ and is precisely the class of all automorphisms whose spectrum is disjoint from $C$. In general the situation is much different.

THEOREM 2. Let $X$ be separable infinite dimensional Hilbert space. Then:

(1) $\mathscr{H} \subset \mathscr{U} \mathscr{E} \subset \mathscr{E} \subset \mathscr{J} \subset \mathscr{B}$;

(2) $\mathscr{H}$ and $\mathscr{U} \mathscr{E}$ are open (in $\mathscr{B}$, in the uniform operator topology) but $\mathscr{E}$ is not;

(3) no class is dense in the next larger.

The tools necessary for the proof are two results on semicontinuity of pieces of the spectrum due to Halmos and Lumer.

Theorem A. [4, Theorem 2] $\Pi(T)$ and $\Lambda(T)$ are upper semicontinuous: to every $T \in \mathscr{B}$ and every open set $G$ containing $\Pi(T)$ [respectively, $\Lambda(T)]$ there corresponds a positive number $\varepsilon$ such that $\Pi(S) \subset G[\Lambda(S) \subset G]$ whenever $\|S-T\|<\varepsilon$.

THEOREM B. [4, Theorem 3] $\Lambda(T) \backslash \Pi(T)$ is lower semicontinuous: to every $T \in \mathscr{B}$ and every compact set $K$ contained in $\Lambda(T) \backslash \Pi(T)$ there corresponds a positive number $\varepsilon$ such that $K \subset \Lambda(S) \backslash \Pi(S)$ whenever $\|S-T\|<\varepsilon$.

Proof of Theorem 2. (2) If $T \in \mathscr{H}$ then $\Lambda(T) \cap C=\varnothing$. By semicontinuity, $\Lambda(S) \cap C=\varnothing$ for $S$ sufficiently near $T$. Since $\mathscr{J}$ is open, $S \in \mathscr{H}$. The proof for $\mathscr{U} \mathscr{E}$ is identical. To see that $\mathscr{E}$ is not open fix an orthonormal base $\left\{e_{n}\right\}_{1}^{\infty}$ and let $T$ be the diagonal operator $T e_{n}=n /(n+1) e_{n}$. $T$ is expansive [2, Example 2]. Given $\varepsilon>0$ let $S e_{n}=T e_{n}$ for $|1-n /(n+1)| \geqq \varepsilon$ and $S e_{n}=e_{n}$ otherwise. Then $\|S-T\|<\varepsilon$ but $S$ is not expansive since $1 \in \Pi_{0}(S)$.

(3) $\mathscr{J}$ is not dense in $\mathscr{B}:$ [3, Problem 109].

$\mathscr{E}$ is not dense in $\mathscr{J}$ : let $\left\{e_{n}\right\}_{-\infty}^{\infty}$ be an orthonormal base and let $T$ be the backward bilaterial weighted shift defined by $T e_{n}=2 e_{n-1}$ for $n \geqq 1, T e_{n}=1 / 2 e_{n-1}$ for $n \leqq 0$. Then [2, Example 4]

$$
\Pi_{0}(T)=\{1 / 2<|\lambda|<2\}
$$

so that $T \notin \mathscr{E}$. Now $\Lambda\left(T^{*}\right) \backslash \Pi\left(T^{*}\right)=\{1 / 2<|\lambda|<2\}$; by Theorem B if $\left\|S^{*}-T^{*}\right\|$ is small then $C \subset \Lambda\left(S^{*}\right) \backslash \Pi\left(S^{*}\right) \subset \Gamma\left(S^{*}\right)$. Hence $C \subset \Pi_{0}(S)$ and $S \notin \mathscr{E}$.

$\mathscr{H}$ is not dense in $\mathscr{U} \mathscr{E}:$ in fact $\mathscr{H} \mathscr{E} \backslash \mathscr{H}$ is open. If $T \in \mathscr{H} \mathscr{E} \backslash \mathscr{H}$ then $\Pi(T) \cap C=\varnothing$ but $\Lambda(T) \cap C \neq \varnothing$. So there exists a compact set $K \subset C \cap[\Lambda(T) \backslash \Pi(T)]$. By Theorem $B, K \subset \Lambda(S)$ for $\|S-T\|$ small, so that $S \notin \mathscr{H}$. 
$\mathscr{C} \mathscr{E}$ is not dense in $\mathscr{E}$ : let $X$ be represented as $H^{2}$ (of the unit circle) and let $T$ be the multiplication operator $T f\left(e^{i t}\right)=\left(e^{i t}+3 / 2\right)$ $f\left(e^{i t}\right)$. Let $A_{r}=\{|\lambda-3 / 2| \leqq r\}$. Either direct calculation or appeal to the spectral properties of Toeplitz operators ([1], for instance) shows that $\Lambda(T)=A_{1}, \Pi_{0}(T)=\varnothing, \Pi(T)=$ bdy $A_{1}$, and $\Gamma(T)=\operatorname{int} A_{1}$. By Theorems A and B there exists $\varepsilon>0$ such that if $\|S-T\|<\varepsilon$ then $A_{3 / 4} \subset \Gamma(S)$ and $\Lambda(S) \subset A_{3 / 2}$. Now the arc $\alpha(t)=e^{i t}, 0 \leqq t \leqq \pi / 2$, on the unit circle has $\alpha(0) \in A_{3 / 4}$ and $\alpha(\pi / 2) \notin A_{3 / 2}$. Thus $\alpha(t) \in$ bdy $\Lambda(S)$ for some $t$; hence $\Pi(S) \cap C \neq \varnothing$ and $S \notin \mathscr{U} \mathscr{E}$. To verify that $T$ is expansive let $a \in[0, \pi]$ with $\left|e^{i a}+3 / 2\right|=1$. Fix $f \in H^{2}$ with $\|f\|_{2}=1$. Then either

$$
1 / 2 \pi \int_{-a}^{a}\left|f\left(e^{i t}\right)\right|^{2} d t \geqq 1 / 2 \text { or } 1 / 2 \pi \int_{a}^{2 \pi-a}\left|f\left(e^{i t}\right)\right|^{2} d t \geqq 1 / 2 .
$$

If the former holds choose $-a<b<c<a$ with

$$
1 / 2 \pi \int_{b}^{c}\left|f\left(e^{i t}\right)\right|^{2} d t \geqq 1 / 4,
$$

let $K=\min \left\{\left|e^{i b}+3 / 2\right|,\left|e^{i c}+3 / 2\right|\right\}>1$, and choose an integer $n$ with $K^{n} \geqq 4$. If $m \geqq n$

$$
\begin{aligned}
\left\|T^{m} f\right\|_{2}^{2} & =1 / 2 \pi \int_{0}^{2 \pi}\left|e^{i t}+3 / 2\right|^{2 m}\left|f\left(e^{i t}\right)\right|^{2} d t \\
& \geqq 1 / 2 \pi \int_{b}^{c}\left|e^{i t}+3 / 2\right|^{2 m}\left|f\left(e^{i t}\right)\right|^{2} d t \\
& \geqq K^{2 m} 1 / 2 \pi \int_{b}^{c}\left|f\left(e^{i t}\right)\right|^{2} d t \\
& \geqq 4
\end{aligned}
$$

If the other alternative holds then $\left\|T^{-m} f\right\|_{2} \geqq 2$ for large $m$. Hence $T$ is expansive.

\section{REFERENCES}

1. P. L. Duren, On the spectrum of a Toeplitz operator, Pacific J. Math., 14 (1964), 21-29.

2. M. Eisenberg and J.H. Hedlund, Expansive automorphisms of Banach spaces, Pacific J. Math., 34 (1970), 647-656.

3. P. R. Halmos, A Hilbert Space Problem Book, Van Nostrand, Princeton, 1967.

4. P. R. Halmos and G. Lumer, Square roots of operators, II, Proc. Amer. Math. Soc., 5 (1954), 589-595.

Received August 3, 1970.

University of Massachusetts, Amherst 



\title{
PACIFIC JOURNAL OF MATHEMATICS
}

\section{EDITORS}

H. SAMELSON

Stanford University

Stanford, California 94305

C. R. HobвY

University of Washington

Seattle, Washington 98105

\section{J. DugunduI}

Department of Mathematics

University of Southern California

Los Angeles, California 90007

RICHARD ARENS

University of California

Los Angeles, California 90024

\section{ASSOCIATE EDITORS}
E. F. BECKENBACH
B. H. Neumann
F. WOLE
K. Yoshida

\section{SUPPORTING INSTITUTIONS}

\author{
UNIVERSITY OF BRITISH COLUMBIA \\ CALIFORNIA INSTITUTE OF TECHNOLOGY \\ UNIVERSITY OF CALIFORNIA \\ MONTANA STATE UNIVERSITY \\ UNIVERSITY OF NEVADA \\ NEW MEXICO STATE UNIVERSITY \\ OREGON STATE UNIVERSITY \\ UNIVERSITY OF OREGON \\ OSAKA UNIVERSITY \\ UNIVERSITY OF SOUTHERN CALIFORNIA
}

\author{
STANFORD UNIVERSITY \\ UNIVERSITY OF TOKYO \\ UNIVERSITY OF UTAH \\ WASHINGTON STATE UNIVERSITY \\ UNIVERSITY OF WASHINGTON

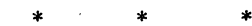 \\ AMERICAN MATHEMATICAL SOCIETY \\ CHEVRON RESEARCH CORPORATION \\ NAVAL WEAPONS CENTER
}

The Supporting Institutions listed above contribute to the cost of publication of this Journal, but they are not owners or publishers and have no responsibility for its content or policies.

Mathematical papers intended for publication in the Pacific Journal of Mathematics should be in typed form or offset-reproduced, (not dittoed), double spaced with large margins. Underline Greek letters in red, German in green, and script in blue. The first paragraph or two must be capable of being used separately as a synopsis of the entire paper. The editorial "we" must not be used in the synopsis, and items of the bibliography should not be cited there unless absolutely necessary, in which case they must be identified by author and Journal, rather than by item number. Manuscripts, in duplicate if possible, may be sent to any one of the four editors. Please classify according to the scheme of Math. Rev. Index to Vol. 39. All other communications to the editors should be addressed to the managing editor, Richard Arens, University of California, Los Angeles, California, 90024.

50 reprints are provided free for each article; additional copies may be obtained at cost in multiples of 50 .

The Pacific Journal of Mathematics is published monthly. Effective with Volume 16 the price per volume (3 numbers) is $\$ 8.00$; single issues, $\$ 3.00$. Special price for current issues to individual faculty members of supporting institutions and to individual members of the American Mathematical Society: $\$ 4.00$ per volume; single issues $\$ 1.50$. Back numbers are available.

Subscriptions, orders for back numbers, and changes of address should be sent to Pacific Journal of Mathematics, 103 Highland Boulevard, Berkeley, California, 94708.

PUBLISHED BY PACIFIC JOURNAL OF MATHEMATICS, A NON-PROFIT CORPORATION

Printed at Kokusai Bunken Insatsusha (International Academic Printing Co., Ltd.), 7-17, Fujimi 2-chome, Chiyoda-ku, Tokyo, Japan. 


\section{Pacific Journal of Mathematics}

\section{Vol. 36, No. $3 \quad$ BadMonth, 1971}

E. M. Alfsen and B. Hirsberg, On dominated extensions in linear subspaces of

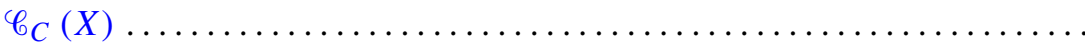

Joby Milo Anthony, Topologies for quotient fields of commutative integral

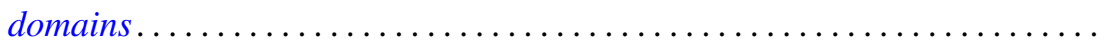

V. Balakrishnan, G. Sankaranarayanan and C. Suyambulingom, Ordered cycle lengths in a random permutation .......................... 603

Victor Allen Belfi, Nontangential homotopy equivalences............... 615

Jane Maxwell Day, Compact semigroups with square roots .............. 623

Norman Henry Eggert, Jr., Quasi regular groups of finite commutative nilpotent algebras .......................................... 631

Paul Erdős and Ernst Gabor Straus, Some number theoretic results ......... 635

George Rudolph Gordh, Jr., Monotone decompositions of irreducible Hausdorff continua .............................................

Darald Joe Hartfiel, The matrix equation $A X B=X \ldots \ldots \ldots \ldots \ldots \ldots . \ldots 69$

James Howard Hedlund, Expansive automorphisms of Banach spaces. II . . . . 671

I. Martin (Irving) Isaacs, The p-parts of character degrees in p-solvable

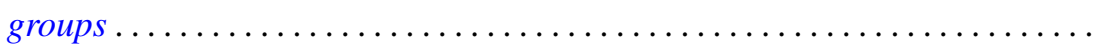

Donald Glen Johnson, Rings of quotients of $\Phi$-algebras ............... 693

Norman Lloyd Johnson, Transition planes constructed from semifield planes....

Anne Bramble Searle Koehler, Quasi-projective and quasi-injective modules.

James J. Kuzmanovich, Completions of Dedekind prime rings as second endomorphism rings...

B. T. Y. Kwee, On generalized translated quasi-Cesàro summability ...

Yves A. Lequain, Differential simplicity and complete integral closure

741

Mordechai Lewin, On nonnegative matrices.

753

Kevin Mor McCrimmon, Speciality of quadratic Jordan algebras ...

Hussain Sayid Nur, Singular perturbations of differential equations in abstract spaces .....................................

D. K. Oates, A non-compact Krein-Milman theorem .

Lavon Barry Page, Operators that commute with a unilateral shift on an invariant subspace...

Helga Schirmer, Properties of fixed point sets on dendrites.

Saharon Shelah, On the number of non-almost isomorphic models of $T$ in a

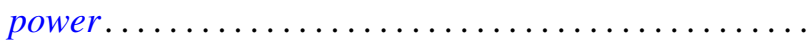

Robert Moffatt Stephenson Jr., Minimal first countable Hausdorff spaces....

Masamichi Takesaki, The quotient algebra of a finite von Neumann algebra 